\title{
Tenofovir-associated bone density loss
}

This article was published in the following Dove Press journal:

Therapeutics and Clinical Risk Management

24 December 2009

Number of times this article has been viewed

\author{
Iwen F Grigsby $1,2,3,4,5$ \\ Lan Pham ${ }^{1,2,4}$ \\ Louis M Mansky,3,5 \\ Raj Gopalakrishnan ${ }^{3,4}$ \\ Kim C Mansky $1,2,4$ \\ 'Division of Orthodontics, \\ ${ }^{2}$ Department of Developmental and \\ Surgical Sciences, ${ }^{3}$ Department of \\ Diagnostic and Biological Sciences, \\ ${ }^{4}$ MinnCResT Program, School of \\ Dentistry, and ${ }^{5}$ Institute for Molecular \\ Virology, Academic Health Center, \\ University of Minnesota, Minneapolis, \\ MN, USA
}

Correspondence: Kim C Mansky University of Minnesota, 16-146 Moos Tower, 5 I 5 Delaware St. SE, Minneapolis, MN 55455, USA

$\mathrm{Tel}+\mathrm{I}$ 6I2-626-5582

Fax + I 612-626-5515

Email kmansky@umn.edu
Abstract: Clinical observations have revealed a strong correlation between loss of bone density in HIV-infected individuals, particularly in conjunction with the antiretroviral drug tenofovir, a nucleotide analog that inhibits HIV reverse transcriptase. The most compelling correlations have been observed in clinical studies involving young children and adolescents. These observations strongly suggest that bone density is being affected during active bone growth and development, implicating a role for tenofovir in bone loss. Here we discuss the literature and potential mechanisms for how tenofovir-associated bone loss may arise, which likely involves perturbation of cellular DNA synthesis and gene expression. Elucidation of the mechanism(s) involved in tenofovir-mediated bone loss will help in developing adjuvant therapies to reduce tenofovir-associated bone density loss.

Keywords: tenofovir, osteoblast, osteoclast, dysfunction, PMPA, renal

\section{Introduction}

Nucleoside reverse transcriptase inhibitors (NRTIs) represent the backbone of highly active antiretroviral therapy (HAART) for the clinical management of human immunodeficiency virus (HIV) infection. NRTIs target HIV reverse transcriptase and prevent the synthesis of viral DNA. NRTIs lack a 3'-hydroxyl group on the deoxyribose and following incorporation of the next incoming deoxynucleotide cannot form the new $5^{\prime}-3^{\prime}$ phosphodiester bond required to extend the synthesis of the DNA chain. Thus, NRTIs act as chain terminators of HIV DNA synthesis. Due to the development of HIV drug resistance, there has been a continual need for the discovery and development of new drug targets and new anti-HIV drugs.

Tenofovir, also called 9-(R)-\{2-(phosphonomethoxy)propyl $\}$ adenine or PMPA, is a nucleotide analog (Figure 1) and was approved in 2001 for use in treating HIV infection and more recently for chronic hepatitis B infection. ${ }^{1}$ The prodrug form is tenofovir disoproxil fumarate (TDF) (Figure 1). Tenofovir has improved potency as it is a nucleotide and has an abbreviated intracellular activation pathway to allow a more rapid and complete conversion to the active drug. The prodrug TDF has a labile lipophilic group to facilitate penetration through target cell membranes. Tenofovir is not known to be a substrate, inducer or inhibitor of human cytochrome P450 enzymes in vitro or in vivo. Tenofovir has high potency and an unusually durable response when used in trials of single-agent therapy intensification in highly treatmentexperienced individuals. ${ }^{2}$ The active metabolite, tenofovir diphosphate, exhibits a long intracellular half-life in both resting and activated peripheral blood mononuclear cells, which allows for single daily dosing. The clinical efficacy of TDF has been 


\section{Tenofovir}<smiles>C[C@H](Cn1cnc2c(N)ncnc21)OCP(=O)(O)O</smiles>

Tenofovir disoproxil fumarate

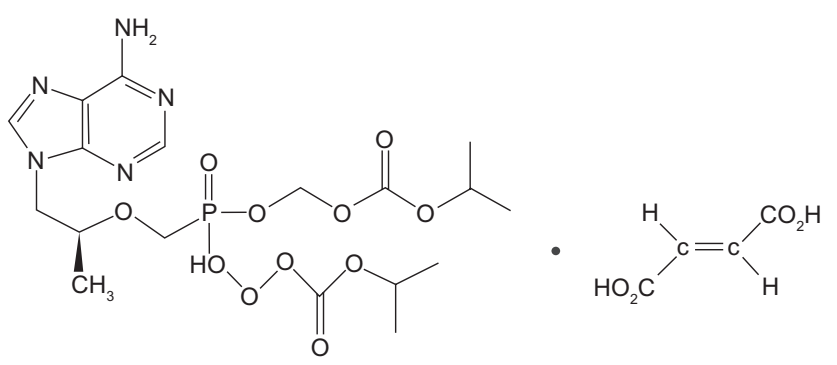

Figure I Structures of tenofovir and tenofovir disoproxil fumarate (TDF).

shown in Phase II (ie, GS-98-902) and III (ie, GS-99-907) clinical trials, with highly treatment-experienced patients. ${ }^{3,4}$ The Phase II and III studies were both randomized, doubleblind, placebo-controlled, multicenter intensification studies of TDF that confirmed the utility of TDF in which patients added TDF therapy (300 mg once daily) in addition to their existing regimen. ${ }^{5}$

While there has been great success in the use of tenofovir in treating HIV infection, there have been clinical reports of tenofovir-associated side effects. Among those side effects, multiple studies have implicated tenofovir-associated bone loss. This review discusses the literature on tenofovirassociated bone loss and presents several plausible mechanisms that might explain the basis for bone loss.

\section{Tenofovir-associated bone loss}

Bone is a dynamic tissue that is formed and maintained by osteoblasts (which form bone) and osteoclasts (which resorb bone). An extensive cell signaling network between osteoblasts and osteoclasts is required for maintaining a balance in the activities of these two cell types in bone remodeling and bone health. Recent studies have indicated that direct signals between bone cells are important for regulating bone remodeling. ${ }^{6-8}$ For example, it has been shown that osteoclasts can initiate bone formation via signaling to osteoblasts independent of their ability to resorb bone., ${ }^{9,10}$ In patients with autosomal dominant osteopetrosis type II it was demonstrated that the number of osteoclasts but not their activity controls bone formation. ${ }^{11}$ Conversely, osteoblasts regulate osteoclast differentiation by expressing two factors that are necessary and sufficient for osteoclast formation: M-CSF ${ }^{12}$ and RANKL ${ }^{13}$; M-CSF is required for survival and proliferation of early osteoclast precursors. ${ }^{14-16}$ Binding of RANKL, produced by osteoblasts, and the RANK receptor on osteoclasts stimulates expression of genes necessary for osteoclast differentiation, cellular fusion and bone resorption. Additionally, osteoblasts express osteoprotegerin, a soluble decoy receptor for RANKL, which inhibits activation of RANK by RANKL. The ratio of RANKL to osteoprotegerin produced by osteoblasts is a major determinant of osteoclast forming activity within the bone microenvironment and allows for close coordination between bone formation and bone resorption under normal physiological conditions.

Perturbations in the function of osteoblasts or osteoclasts can lead to bone loss, clinically presented as osteopenia or osteoporosis. Osteoporosis commonly occurs in women following menopause, where it is called postmenopausal osteoporosis, but can also occur in men or anyone with certain hormonal disorders, other chronic diseases, or due to medications such as glucocorticoids. ${ }^{17-23}$ Vitamin D deficiencies can result in bone softening, resulting in osteomalacia - in children called rickets. ${ }^{24-26}$ Loss of osteoclast function increases bone density, resulting in osteopetrosis. One example of a human condition involving osteopetrosis is a rare inherited disorder, called Albers-Schonberg disease. In osteopetrosis, osteoclast numbers may be lower, normal, or elevated, however the critical factor in the development of osteopetrosis is the dysfunction of osteoclasts. For example, a reduction of carbonic anhydrase expression in osteoclasts can result in defects in hydrogen ion pumping, which can cause a dysfunction in osteoclast resorption of bone. ${ }^{27,28}$ However, osteoblast dysfunction, particularly hyperactivity, can also result in osteopetrosis ${ }^{29,30}$ while a decrease in function can contribute to osteoporosis.

HIV infection has been implicated as a risk factor for alteration of bone mineral density in children as well as in adults. ${ }^{31-34}$ Imbalances in growth factors and cytokines, as well as the use of HAART could contribute to bone loss by increasing bone resorption. Previous studies have demonstrated adverse effects on bone metabolism by the administration of tenofovir in macaques, resulting primarily in decreased bone density. ${ }^{35-37}$ Infection of macaques by simian immunodeficiency virus was also implicated in affecting bone density. Histomorphometric analysis revealed in one of these studies an increase in tibial osteoid seam width, which can result in bone softening (and can develop 
into osteomalacia). ${ }^{35}$ The increase in osteoid seam width is likely associated with reduced activity in osteoblasts. Bone density reductions due to tenofovir have also been reported in human adults. ${ }^{38}$ Since tenofovir has a distinct and unique drug resistance profile, it satisfies the significant need for new non-cross-resistant HAART regimens in salvage therapy, particularly with children and adolescents. In light of this, offlabel clinical studies of tenofovir with HIV-infected children and adolescents have been conducted to investigate the efficacy of tenofovir-containing HAART regimens and to investigate whether tenofovir-associated bone loss is greater in children and adolescents than in adults. ${ }^{39-41}$ Increased bone resorption could cause a compensatory increase in osteoblast activity, which would be revealed by increased serum alkaline phosphatase levels. ${ }^{42}$ General conclusions drawn from these studies include that tenofovir treatment decreased bone mineral density as well as increased urinary calcium excretion. One limitation of these studies was the relatively small study size (ranging from 18 to 6 children). Another limitation of these studies is that the measurement of bone density is difficult in children and adolescents because of the dynamic yet variable rate of bone growth. Presently, there are different methods that are commonly used to measure bone density: dual-energy X-ray absorbtiometry (DXA), quantitative computed tomography (QCT), and quantitative ultrasound (QUS). Each approach has limitations and comparisons between these methods are difficult as comparative data analysis can be somewhat subjective. A study that analyzed the effect of TDF treatment of a group of 16 HIV-infected children and adolescents over a 1-year period concluded that TDF did not affect bone density when stavudine and protease inhibitor-containing regimens were compared with TDF/lamivudine/efavirenz. ${ }^{43}$ Differences in this study compared to that of the previously described studies include that the patients were older, had greater height and weight, and the majority were either in middle or late puberty or postpubertal. The children under study were also required to have long-lasting viral suppression prior to the switch to TDF and were exposed to TDF levels that may have been lower, as fractions of pills were administered. This study design is different to the other studies, which involved relatively younger children that did not have long lasting viral suppression prior to the switch to TDF, which were entire pills (ie, $300 \mathrm{mg}$ ). ${ }^{39-41}$

\section{Mechanisms of tenofovir-associated bone loss}

A significant literature exists on NRTIs that have implicated mitochondrial dysfunction, reviewed in. ${ }^{44-49}$ The inhibition of mitochondrial polymerase gamma could occur by competitive inhibition of polymerase gamma and/or the incorporation and subsequent DNA chain termination. The result would be a reduction in mitochondrial DNA synthesis. NRTIs could also indirectly inhibit DNA synthesis by inducing nucleotide pool imbalances, oxidative stress, and DNA damage. Both direct and indirect mechanisms would result in the alteration of mitochondrial gene expression, which would cause mitochondrial dysfunction. NRTIs have greater affinity for affecting different tissue types as well as the nature of the mitochondrial-induced dysfunction in these tissue types, depending upon the NRTI. The analysis of NRTI-associated cellular stress has indicated that the mechanisms involved can be quite complex. NRTIs can result in altered gene expression profiles. ${ }^{50,51}$ Altered gene expression profiles have been observed in the absence of mitochondrial DNA depletion, suggesting that NRTIs can cause mitochondrial dysfunction and not inhibit mitochondrial DNA polymerase gamma. ${ }^{52}$

The association of tenofovir with mitochondrial dysfunction has been investigated. In general, no mitochondrial dysfunction was observed with tenofovir. ${ }^{53-56}$ Other studies have reported a lowering of mitochondrial dysfunction when drug regimens were changed and NRTIs were replaced with tenofovir. ${ }^{57-59} \mathrm{~A}$ recent study in rats found that very high doses (ie, $100 \mathrm{mg} / \mathrm{kg} /$ day) of tenofovir reduced mitochondrial DNA and gene expression in kidney cells. ${ }^{60}$ The relevance of this observation given the very high dosing used is unclear. In stark contrast, in an HIV transgenic mouse model tenofovir treatment was found to increase mitochondrial DNA content in kidney cells. ${ }^{61}$ Further analysis of mitochondrial DNA obtained from renal proximal tubules microdissected from kidney sections suggested that tenofovir lowered mitochondrial DNA levels in the renal proximal tubules. ${ }^{61}$ To date, no studies of mitochondrial dysfunction being associated with tenofovir-mediated bone loss have been reported. Overall, the current literature does not provide strong evidence for mitochondrial dysfunction being a major mechanism for tenfovirmediated cellular stress, particularly in regards to bone loss.

In vitro studies have previously reported that tenofovir diphosphate is a poor substrate and weak inhibitor of rat DNA polymerase alpha, delta and epsilon. ${ }^{55}$ Combined with the report of tenofovir diphosphate being poorly incorporated into DNA by the human mitochondrial DNA polymerase gamma, ${ }^{49}$ data are limited that would support a direct role of tenofovir in bone loss by the inhibition of either nuclear or mitochondrial DNA replication. While data are lacking for tenofovir diphosphate being a good substrate for cellular DNA polymerases, the in vivo data correlating 
tenofovir therapy with bone loss, particularly in children and adolescents who have very active and ongoing bone growth, implicate a role for tenofovir's ability to impact cellular DNA synthesis. Such an impact could be either direct or indirect, such as 1) incorporation and DNA chain termination, 2) DNA damage, 3) alteration of deoxynucleotide transport, and/or 4) nucleotide pool imbalances, which would perturb cellular DNA synthesis. The perturbation of cellular (ie, nuclear and/or mitochondrial) DNA synthesis would result in altered gene expression. The alteration of gene expression for genes involved in bone maintenance could explain the clinical observation of bone density loss during tenofovir treatment.

We propose three potential mechanisms for tenofovirassociated bone loss. These include 1) preferential uptake by osteoclasts (altering gene expression and resulting in increased bone resorption), 2) update by osteoblasts (altering gene expression and decreasing bone formation), and 3) uptake by both osteoclasts and osteoblasts (altering gene expression of both cells types and ultimately the balance between bone resorption and bone formation - resulting in bone loss).
Since TDF is a phosphonate, it is possible that this could enhance its uptake into cells (Figure 2A), which would increase the probability of cellular stress. Bisphosphonates (ie, diphosphonates) are drugs used clinically to prevent loss of bone density, particularly in diseases such as osteoporosis, bone metastasis, multiple myeloma, Paget's disease of bone, and primary hyperparathyroidism. Bisphosphonates target bone and inhibit osteoclast function after their cellular uptake by inducing apoptosis. ${ }^{62,63}$ Since tenofovir and TDF are both phosphonates, it is conceivable that they could also have an association with bone and be selectively taken up by osteoclasts by a mechanism similar to that of bisphosphonates, ultimately causing cellular stress. The resulting cellular stress would likely perturb cellular DNA synthesis (ie, nuclear and/or mitochondrial) and gene expression (Figure 2B). For example, the reduction of gene expression for an osteoclast gene that is involved in signaling osteoblast activity could ultimately result in a loss of bone density. It is formally possible that adjuvant treatment of bone density loss could improve the durability of tenofovir-containing HAART. In the case of osteoclast hyperactivity, it is possible that

A

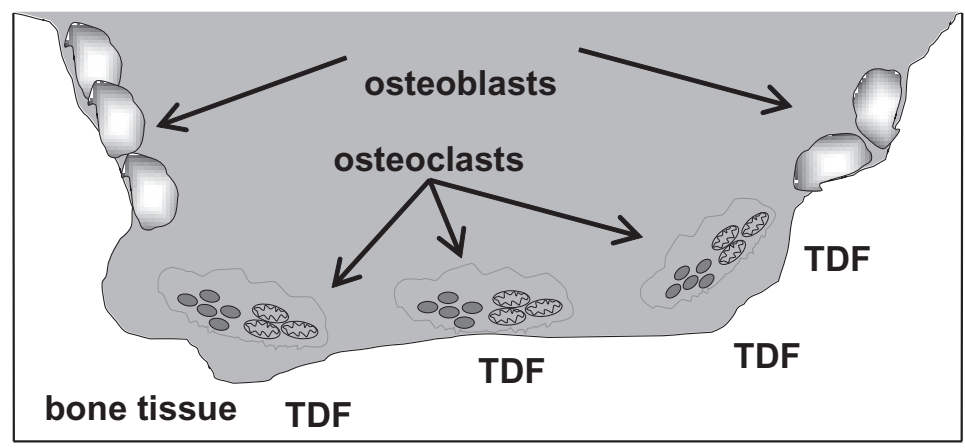

B

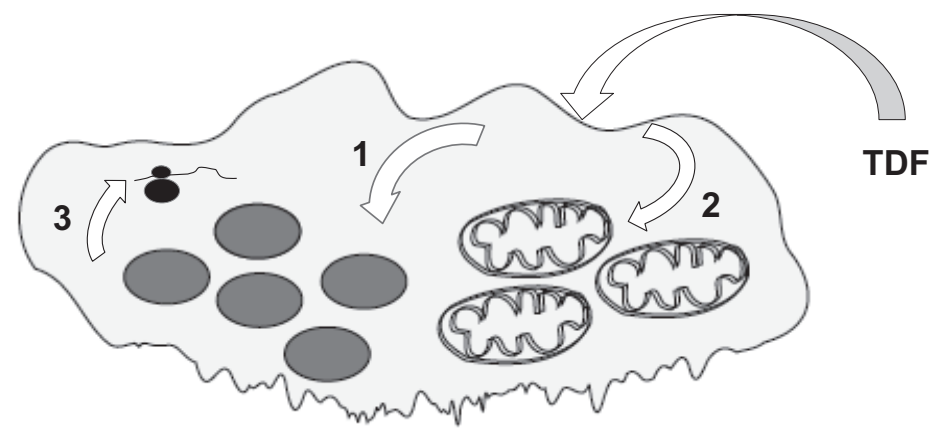

Multinucleated osteoclast

Figure 2 The osteoclast as a target for TDF. A) Bone tissue, osteoblasts and osteoclasts. TDF, as a phosphonate, associates with bone tissue. Bone resorption by osteoclasts would result in the preferential uptake of TDF. B) Impact of TDF on osteoclast DNA synthesis and gene expression. Following TDF uptake by osteoclasts, TDF can target the nucleus (I) and/or mitochondria (2), where it may directly or indirectly perturb DNA synthesis by I) incorporation and DNA chain termination, 2) DNA damage, 3) alteration of deoxynucleotide transport, and/or 4) nucleotide pool imbalances. The impact of TDF on cellular DNA synthesis would result in altered gene expression (3). Abbreviation: TDF, tenofovir disoproxil fumarate. 
bisphosphonates could reduce bone density loss associated with tenofovir treatment.

The loss of bone density due to TDF exposure could also be associated with tenofovir-induced renal dysfunction particularly renal proximal tubule dysfunction. ${ }^{42,61,64-72}$ The failure of renal proximal tubular cells to reabsorb filtered bicarbonate from the urine would result in urinary bicarbonate wasting and subsequent acidemia and a more general dysfunction of the proximal tubular cells - called Fanconi's syndrome. Commonly observed conditions in Fanconi syndrome include aminoaciduria, glycosuria, tubular proteinuria, and uricosuria. Importantly, the main clinical feature of Fanconi's syndrome is bone demineralization (osteomalacia or rickets) due to phosphate wasting. Therefore, TDF-associated bone density loss may an outcome of renal dysfunction.

\section{Summary}

The distinctive resistance profile, high potency and limited side effects of tenofovir have made it an important component of HAART. The off-label use of tenofovir for treatment of children and adolescents is important for providing alternatives to treatment-experienced patients. Also, tenofovir will likely play an important role in preventing mother-to-child transmission, particularly in the context of the appeal of TDF-containing fixed dose combinations in a single pill (ie, Atripla ${ }^{\circledR}$ and Truvada ${ }^{\circledR}$ ). A concern in off-label tenofovir use is bone density loss. Current data indicate that tenofovirmediated bone loss is likely mediated by novel mechanisms not solely related to the known mitochondrial dysfunction associated with NRTIs. Future research will further aid in the elucidation the mechanism(s) involved in tenofovir-mediated bone loss, which would help in developing adjuvant therapies to reduce tenofovir-associated bone density loss.

\section{Acknowledgments}

We thank Steve Patterson for stimulating discussions. Supported by NIH grants AR53946 (K.C.M.), DE16093 (R.G.), and GM56615 (L.M.M.). I.F.G. and L.P. were supported by the MinnCResT Program, T32DE07288.

\section{Disclosures}

The authors declare no conflicts of interest.

\section{References}

1. Pozniak A. Tenofovir: what have over 1 million years of patient experience taught us? Int J Clin Pract. 2008;62(8):1285-1293.

2. Stephan C. Experience with tenofovir disoproxil fumarate for antiretroviral therapy. Expert Opin Pharmacother. 2008;9(7):1197-1209.
3. Margot NA, Isaacson E, McGowan I, Cheng AK, Schooley RT, Miller MD. Genotypic and phenotypic analyses of HIV-1 in antiretroviralexperienced patients treated with tenofovir DF. AIDS. 2002;16(9): $1227-1235$.

4. Schooley RT, Ruane P, Myers RA, et al. Tenofovir DF in antiretroviralexperienced patients: results from a 48-week, randomized, doubleblind study. AIDS. 2002;16(9):1257-1263.

5. Squires K, Pozniak AL, Pierone G Jr, et al. Tenofovir disoproxil fumarate in nucleoside-resistant HIV-1 infection: a randomized trial. Ann Intern Med. 2003;139(5 Pt 1):313-320.

6. Karsdal MA, Martin TJ, Bollerslev J, Christiansen C, Henriksen K. Are nonresorbing osteoclasts sources of bone anabolic activity? J Bone Miner Res. 2007;22(4):487-494.

7. Karsdal MA, Henriksen K, Sorensen MG, et al. Acidification of the osteoclastic resorption compartment provides insight into the coupling of bone formation to bone resorption. Am J Pathol. 2005;166(2):467-476.

8. Martin TJ, Sims NA. Osteoclast-derived activity in the coupling of bone formation to resorption. Trends Mol Med. 2005;11(2):76-81.

9. Bollerslev J, Marks SC Jr, Pockwinse S, et al. Ultrastructural investigations of bone resorptive cells in two types of autosomal dominant osteopetrosis. Bone. 1993;14(6):865-869.

10. Bollerslev J, Steiniche T, Melsen F, Mosekilde L. Structural and histomorphometric studies of iliac crest trabecular and cortical bone in autosomal dominant osteopetrosis: a study of two radiological types. Bone. 1989;10(1):19-24.

11. Alatalo SL, Ivaska KK, Waguespack SG, Econs MJ, Vaananen HK, Halleen JM. Osteoclast-derived serum tartrate-resistant acid phosphatase $5 \mathrm{~b}$ in Albers-Schonberg disease (type II autosomal dominant osteopetrosis). Clin Chem. 2004;50(5):883-890.

12. Cecchini MG, Hofstetter W, Halasy J, Wetterwald A, Felix R. Role of CSF-1 in bone and bone marrow development. Mol Reprod Dev. 1997;46(1):75-83; discussion 83-74.

13. Wada T, Nakashima T, Hiroshi N, Penninger JM. RANKL-RANK signaling in osteoclastogenesis and bone disease. Trends Mol Med. 2006;12(1):17-25.

14. Felix R, Cecchini MG, Hofstetter W, Elford PR, Stutzer A, Fleisch H. Impairment of macrophage colony-stimulating factor production and lack of resident bone marrow macrophages in the osteopetrotic op/op mouse. J Bone Miner Res. 1990;5(7):781-789.

15. Wiktor-Jedrzejczak W, Bartocci A, Ferrante AW Jr, et al. Total absence of colony-stimulating factor 1 in the macrophage-deficient osteopetrotic (op/op) mouse. Proc Natl Acad Sci U S A. 1990;87(12):4828-4832.

16. Yoshida H, Hayashi S, Kunisada T, et al. The murine mutation osteopetrosis is in the coding region of the macrophage colony stimulating factor gene. Nature. 1990;345(6274):442-444.

17. Bonnelye E, Merdad L, Kung V, Aubin JE. The orphan nuclear estrogen receptor-related receptor alpha (ERRalpha) is expressed throughout osteoblast differentiation and regulates bone formation in vitro. $J$ Cell Biol. 2001;153(5):971-984.

18. Liu RH, Werth VP. What is new in the treatment of steroid-induced osteoporosis? Semin Cutan Med Surg. 2007;26(4):203-209.

19. Shaker JL, Lukert BP. Osteoporosis associated with excess glucocorticoids. Endocrinol Metab Clin North Am. 2005;34(2):341-356, viii-ix.

20. Caplan L, Saag KG. Glucocorticoids and the risk of osteoporosis. Expert Opin Drug Saf. 2009;8(1):33-47.

21. Ebeling PR. Osteoporosis in men. New insights into aetiology, pathogenesis, prevention and management. Drugs Aging. 1998;13(6):421-434.

22. McIlwain HH. Glucocorticoid-induced osteoporosis: pathogenesis, diagnosis, and management. Prev Med. 2003;36(2):243-249.

23. Pietschmann P, Rauner M, Sipos W, Kerschan-Schindl K. Osteoporosis: an age-related and gender-specific disease - a mini-review. Gerontology. 2008;55(1):3-12.

24. Frame B, Parfitt AM. Osteomalacia: current concepts. Ann Intern Med. 1978;89(6):966-982.

25. Misra M, Pacaud D, Petryk A, Collett-Solberg PF, Kappy M. Vitamin D deficiency in children and its management: review of current knowledge and recommendations. Pediatrics. 2008;122(2):398-417. 
26. Ukinc K. Severe osteomalacia presenting with multiple vertebral fractures: a case report and review of the literature. Endocrine. 2009;36(1):30-36.

27. Segovia-Silvestre T, Neutzsky-Wulff AV, Sorensen MG, et al. Advances in osteoclast biology resulting from the study of osteopetrotic mutations. Hum Genet. 2009;124(6):561-577.

28. Sly WS, Hewett-Emmett D, Whyte MP, Yu YS, Tashian RE. Carbonic anhydrase II deficiency identified as the primary defect in the autosomal recessive syndrome of osteopetrosis with renal tubular acidosis and cerebral calcification. Proc Natl Acad Sci U S A. 1983;80(9): 2752-2756.

29. Boyden LM, Mao J, Belsky J, et al. High bone density due to a mutation in LDL-receptor-related protein 5. N Engl J Med. 2002;346(20): 1513-1521.

30. Van Wesenbeeck L, Cleiren E, Gram J, et al. Six novel missense mutations in the LDL receptor-related protein 5 (LRP5) gene in different conditions with an increased bone density. Am J Hum Genet. 2003;72(3):763-771.

31. Arpadi SM, Horlick M, Thornton J, Cuff PA, Wang J, Kotler DP. Bone mineral content is lower in prepubertal HIV-infected children. J Acquir Immune Defic Syndr. 2002;29(5):450-454.

32. Tebas P, Powderly WG, Claxton S, et al. Accelerated bone mineral loss in $\mathrm{HIV}$-infected patients receiving potent antiretroviral therapy. AIDS. 2000;14(4):F63-F67.

33. Vigano A, Mora S. Adverse effects of antiretroviral therapy: focus on bone density. Expert Opin Drug Saf. 2004;3(3):199-208.

34. Madeddu G, Spanu A, Solinas P, et al. Bone mass loss and vitamin D metabolism impairment in HIV patients receiving highly active antiretroviral therapy. $Q \mathrm{~J} \mathrm{Nucl}$ Med Mol Imaging. 2004;48(1): 39-48.

35. Castillo AB, Tarantal AF, Watnik MR, Martin RB. Tenofovir treatment at $30 \mathrm{mg} / \mathrm{kg} /$ day can inhibit cortical bone mineralization in growing rhesus monkeys (Macaca mulatta). J Orthop Res. 2002;20(6): 1185-1189.

36. Tarantal AF, Marthas ML, Shaw JP, Cundy K, Bischofberger N. Administration of 9-[2-(R)-(phosphonomethoxy)propyl]adenine (PMPA) to gravid and infant rhesus macaques (Macaca mulatta): safety and efficacy studies. J Acquir Immune Defic Syndr Hum Retrovirol. 1999;20(4):323-333.

37. Van Rompay KK, Brignolo LL, Meyer DJ, et al. Biological effects of short-term or prolonged administration of 9-[2-(phosphonomethoxy) propyl]adenine (tenofovir) to newborn and infant rhesus macaques. Antimicrob Agents Chemother. 2004;48(5):1469-1487.

38. Gallant JE, Staszewski S, Pozniak AL, et al. Efficacy and safety of tenofovir DF vs stavudine in combination therapy in antiretroviral-naive patients: a 3-year randomized trial. JAMA. 2004;292(2):191-201.

39. Hazra R, Gafni RI, Maldarelli F, et al. Tenofovir disoproxil fumarate and an optimized background regimen of antiretroviral agents as salvage therapy for pediatric HIV infection. Pediatrics. 2005;116(6): e846-e854.

40. Gafni RI, Hazra R, Reynolds JC, et al. Tenofovir disoproxil fumarate and an optimized background regimen of antiretroviral agents as salvage therapy: impact on bone mineral density in HIV-infected children. Pediatrics. 2006;118(3):e711-e718.

41. Purdy JB, Gafni RI, Reynolds JC, Zeichner S, Hazra R. Decreased bone mineral density with off-label use of tenofovir in children and adolescents infected with human immunodeficiency virus. J Pediatr. 2008;152(4):582-584.

42. Fux CA, Rauch A, Simcock M, et al. Tenofovir use is associated with an increase in serum alkaline phosphatase in the Swiss HIV Cohort Study. Antivir Ther. 2008;13(8):1077-1082.

43. Giacomet V, Mora S, Martelli L, Merlo M, Sciannamblo M, Vigano A. A 12-month treatment with tenofovir does not impair bone mineral accrual in HIV-infected children. J Acquir Immune Defic Syndr. 2005; 40(4):448-450.

44. Cote HC. Mechanisms of antiretroviral therapy-induced mitochondrial dysfunction. Curr Opin HIV AIDS. 2007;2(4):253-260.
45. Lewis W, Copeland WC, Day BJ. Mitochondrial dna depletion, oxidative stress, and mutation: mechanisms of dysfunction from nucleoside reverse transcriptase inhibitors. Lab Invest. 2001;81(6):777-790.

46. Lewis W, Day BJ, Copeland WC. Mitochondrial toxicity of NRTI antiviral drugs: an integrated cellular perspective. Nat Rev Drug Discov. 2003;2(10):812-822.

47. Lewis W, Kohler JJ, Hosseini SH, et al. Antiretroviral nucleosides, deoxynucleotide carrier and mitochondrial DNA: evidence supporting the DNA pol gamma hypothesis. AIDS. 2006;20(5):675-684

48. Kohler JJ, Lewis W. A brief overview of mechanisms of mitochondrial toxicity from NRTIs. Environ Mol Mutagen. 2007;48(3-4):166-172.

49. Lee H, Hanes J, Johnson KA. Toxicity of nucleoside analogues used to treat AIDS and the selectivity of the mitochondrial DNA polymerase. Biochemistry. 2003;42(50):14711-14719.

50. Desai VG, Lee T, Delongchamp RR, et al. Nucleoside reverse transcriptase inhibitors (NRTIs)-induced expression profile of mitochondriarelated genes in the mouse liver. Mitochondrion. 2008;8(2):181-195.

51. Desai VG, Lee T, Moland CL, et al. Effect of short-term exposure to zidovudine (AZT) on the expression of mitochondria-related genes in skeletal muscle of neonatal mice. Mitochondrion. 2009;9(1): 9-16.

52. Mallon PW, Unemori P, Sedwell R, et al. In vivo, nucleoside reversetranscriptase inhibitors alter expression of both mitochondrial and lipid metabolism genes in the absence of depletion of mitochondrial DNA. J Infect Dis. 2005;191(10):1686-1696.

53. Vidal F, Domingo JC, Guallar J, et al. In vitro cytotoxicity and mitochondrial toxicity of tenofovir alone and in combination with other antiretrovirals in human renal proximal tubule cells. Antimicrob Agents Chemother. 2006;50(11):3824-3832.

54. Cihlar T, Birkus G, Greenwalt DE, Hitchcock MJ. Tenofovir exhibits low cytotoxicity in various human cell types: comparison with other nucleoside reverse transcriptase inhibitors. Antiviral Res. 2002;54(1): 37-45.

55. Birkus G, Hitchcock MJ, CihlarT. Assessment of mitochondrial toxicity in human cells treated with tenofovir: comparison with other nucleoside reverse transcriptase inhibitors. Antimicrob Agents Chemother. 2002;46(3):716-723.

56. Biesecker G, Karimi S, Desjardins J, et al. Evaluation of mitochondrial DNA content and enzyme levels in tenofovir DF-treated rats, rhesus monkeys and woodchucks. Antiviral Res. 2003;58(3):217-225.

57. Gerschenson M, Kim C, Berzins B, et al. Mitochondrial function, morphology and metabolic parameters improve after switching from stavudine to a tenofovir-containing regimen. J Antimicrob Chemother. 2009;63(6):1244-1250.

58. Ribera E, Paradineiro JC, Curran A, et al. Improvements in subcutaneous fat, lipid profile, and parameters of mitochondrial toxicity in patients with peripheral lipoatrophy when stavudine is switched to tenofovir (LIPOTEST study). HIV Clin Trials. 2008;9(6):407-417.

59. Miro O, Garrabou G, Lopez S, et al. Short communication metabolic and mitochondrial effects of switching antiretroviral-experienced patients to enfuvirtide, tenofovir and saquinavir/ritonavir. Antivir Ther. 2006;11(5):625-630.

60. Lebrecht D, Venhoff AC, Kirschner J, Wiech T, Venhoff N, Walker UA. Mitochondrial tubulopathy in tenofovir disoproxil fumarate-treated rats. J Acquir Immune Defic Syndr. 2009;51(3):258-263.

61. Kohler JJ, Hosseini SH, Hoying-Brandt A, et al. Tenofovir renal toxicity targets mitochondria of renal proximal tubules. Lab Invest. 2009;89(5):513-519.

62. Kwak HB, Kim JY, Kim KJ, et al. Risedronate directly inhibits osteoclast differentiation and inflammatory bone loss. Biol Pharm Bull. 2009;32(7):1193-1198.

63. Moreau MF, Guillet C, Massin P, et al. Comparative effects of five bisphosphonates on apoptosis of macrophage cells in vitro. Biochem Pharmacol. 2007;73(5):718-723.

64. Earle KE, Seneviratne T, Shaker J, Shoback D. Fanconi's syndrome in HIV+ adults: report of three cases and literature review. J Bone Miner Res. 2004;19(5):714-721. 
65. Parsonage MJ, Wilkins EG, Snowden N, Issa BG, Savage MW. The development of hypophosphataemic osteomalacia with myopathy in two patients with HIV infection receiving tenofovir therapy. HIV Med. 2005;6(5):341-346.

66. Williams J, Chadwick DR. Tenofovir-induced renal tubular dysfunction presenting with hypocalcaemia. J Infect. 2006;52(4):e107-e108.

67. Nelson MR, Katlama C, Montaner JS, et al. The safety of tenofovir disoproxil fumarate for the treatment of HIV infection in adults: the first 4 years. AIDS. 2007;21(10):1273-1281.

68. Labarga P, Barreiro P, Martin-Carbonero L, et al. Kidney tubular abnormalities in the absence of impaired glomerular function in HIV patients treated with tenofovir. AIDS. 2009;23(6):689-696.
69. Woodward CL, Hall AM, Williams IG, et al. Tenofovir-associated renal and bone toxicity. HIV Med. 2009;10(8):482-487.

70. Perrot S, Aslangul E, Szwebel T, Caillat-Vigneron N, Le Jeunne C. Bone pain due to fractures revealing osteomalacia related to tenofovir-induced proximal renal tubular dysfunction in a human immunodeficiency virusinfected patient. J Clin Rheumatol. 2009;15(2):72-74.

71. Calmy A, Fux CA, Norris R, et al. Low bone mineral density, renal dysfunction, and fracture risk in HIV infection: a cross-sectional study. J Infect Dis. 2009;200(11):1746-1754.

72. Di Biagio A, Rosso R, Monteforte P, Russo R, Rovetta G, Viscoli C. Whole body bone scintigraphy in tenofovir-related osteomalacia: a case report. J Med Case Reports. 2009;3:8136.

\section{Publish your work in this journal}

Therapeutics and Clinical Risk Management is an international, peerreviewed journal of clinical therapeutics and risk management, focusing on concise rapid reporting of clinical studies in all therapeutic areas, outcomes, safety, and programs for the effective, safe, and sustained use of medicines. This journal is indexed on PubMed Central, CAS,

\section{Dovepress}

EMBase, Scopus and the Elsevier Bibliographic databases. The manuscript management system is completely online and includes a very quick and fair peer-review system, which is all easy to use. Visit $\mathrm{http} / / / \mathrm{www}$.dovepress.com/testimonials.php to read real quotes from published authors.

Submit your manuscript here: http://www.dovepress.com/therapeutics-and-clinical-risk-management-journal 